It would further seem to be a general principle that when two regions of markedly different growth-rate exist in an organ or region, there is a graded change of growth-rate in the intermediate space. The biochemical basis of such graded differences in growthrate should be interesting to investigate.

JULIAN S. HuXley.

King's College, London, April 3.

\section{Difference between the Absorption and the Raman Spectrum.}

SeVEral investigators have recently stated that in many cases Raman lines are found which do not correspond with infra-red absorption frequencies (Carelli, Pringsheim, and Rosen, Zs. f. Phys., 51, p. 511; 1928: Czerny, ibid., 53, p. 317; 1929: MeLennan and MeLeod, Nature, 123, p. 160; 1929 : Ellis, ibid., p. 205 : Rasetti, ibid., 205 : R. W. Wood, ibid., p. 279, and others). Several authors state this as contrary to the theoretical expectations. The purpose of this note is to direct attention to the fact that the abovementioned phenomena, far from being a contradiction to the theory, really furnish a very good proof for the validity of the Kramers' theory of dispersion, which includes the theory of the Raman effect.

If we consider two levels $A_{1}$ and $A_{2}$ we have absorption if the transition coefficient $a_{12}$ is different from zero. But this coefficient does not enter at all into the expression which determines, according to Kramers and Heisenberg, the intensity of the Raman line. From the fact that this coefficient is zero, one cannot therefore conclude that the corresponding Raman line must be absent and vice versa. The intensity of the Raman lines is determined by the transition coefficients to levels $B_{1}, B_{2}, B_{3}$, etc., which can combine with both $A_{1}$ and $A_{2}$. The Raman frequency can therefore always be regarded as the difference between the frequencies of two lines, one of which must be an absorption line, and this in agreement with the results of Rasetti and especially with those of McLennan and McLeod. A very good example is also furnished by the beautiful results of Wood in hydrochloric acid. Wood finds that the so-called missing line occurs with great intensity in the modified radiation, whereas the real lines of the absorption band are faint and doubtful.

This is exactly what we must expect. For let us consider a hydrochloric acid molecule in a definite rotational state $j$, and confine ourselves to the different vibrational and rotational states of the normal molecule. Then there is, on account of the selection rule for $j$, not a single state which can combine at the same time with the $j$ and the $j \pm 1$ rotational state, or differently expressed, an absorption line of the $\mathrm{HCl}$ band cannot be written as the difference of two other lines and therefore ought not to occur in the Raman spectrum. On the other hand, every transition in which the rotational quantum number $j$ does not change or varies two units (the vibrational quantum number varies from zero to one for all lines under consideration) can be written in more than one way as a difference of two line frequencies. We must, therefore, expect these frequencies in the Raman spectrum rather than the frequencies of the absorption band. The transitions in which $j$ does not change give the 'missing line' and are forbidden as absorption lines. Raman lines corresponding to transitions $j \rightarrow j \pm 2$ must be expected very much weaker, as they are distinct lines for different values of $j$ with twice the distance of the absorption lines, whereas all the $j \rightarrow j$ transitions correspond to lines which coincide on. the place of the zero line and give rise, therefore, to one intensive line. This seems to be in agreement with Wood's observations. Rotational transitions $j \rightarrow j+2$ of the expected type seem to have been observed by McLennan and McLeod in $\mathrm{H}_{2}$. If also the ultra-violet absorption bands, of which nothing is known, are taken into account, these considerations have to be modified a little. But from the general structure of the molecular terms it can be deduced that, for diatomic molecules at least, an absorption line never can be expected as a Raman line. Apparent exceptions to this rule find their explanation in an unresolved fino structure.

With the same considerations one sees that scattering in sodium vapour ought to give a shift corresponding with the forbidden line $1 s-2 s$ rather than with the absorption line $1 s-2 p$.

Since the above was written, I have seen the letter by Langer in NaTURE of Mar. 9, p. 345, in which he makes essentially the same observation. But as he treats only a rather complex example and proceeds according to somewhat different lines of reasoning, the present note is perhaps not superfluous. It ought to be mentioned also that Schrödinger's theory of dispersion in its original form is, contrary to Langer's statement, not in agreement with the facts, whereas the present form of quantum mechanics (Dirac) leads exactly to Kramers and Heisenberg's results.

Natuurkundig Laboratorium der G. H. Dieke.

Rijksuniversiteit, Groningen, Holland, Mar. 8.

\section{Breeding Habits of the Greenland Whale.}

VERY little is known about the breeding habits of the Greenland whale. In the Greenland Sea, according to the log-books of Scoresby Sen., females with calves with them were seldom seen except in spring, west of Spitsbergen, north of latitude $78^{\circ}$ or $79^{\circ}$, and in the end of July off the Greenland coast. Young whales, with whalebone 2-3 feet long-the smallest which are seen by themselves-were also seldom seen except in a high latitude west of Spitsbergen in spring. Where they go to in the summer months is not hard to understand: as my father says, "the old females with the younger whales of both sexes bury themselves in the polar ice, north of latitude $80^{\circ}$, after (or before) the end of June, where no ship can follow them; retreating in the autumn southwards as the ice makes in the north" (Scottish Fishery Board; Seventh Annual Report, part 3, p. 366).

A female with a calf with it became a rare sight in the Greenland Sea ; in twelve voyages (1791-1798, $1801,1817,1820$, and 1822) Scoresby Sen. saw one only on sixteen dates, namely, west of Spitsbergen, and north of $78^{\circ}$ or $79^{\circ}$ in April once, in May eleven times, and in June once; and off Greenland twice, both times at the end of July, in latitude $70^{\circ}$; in the forty-four voyages he was master (1849-1891' and 1893) my father only saw about a dozen (l.c., p. 365), and in his last twenty voyages only one (in the end of July in latitude $73^{\circ}$ off the Greenland Coast), and in the log-books of twenty-nine other voyages made in the period 1872-1908 not a single instance is recorded.

There are few facts to go on, but it seems safe to infer from what the Scoresbys and from what Eschricht and Reinhardt say, that at least some of the young are produced in the spring. Even less is known about where they produce; at one time they entered the inlets of western Spitsbergen in the summer months, and Sir Sidney Harmer (Proc. Linn. Soc., May 1928, p. 89) connects their visits with the function of

No. 3102 , VoL. 123] 